\title{
Research School for Animal Production and Health (RAPH) - A Description of a Danish Research Education Initiative
}

\author{
By Pia Haubro Andersen \\ Department of Clinical Studies, The Royal Veterinary and Agricultural University, Frederiksberg, Denmark.
}

\begin{abstract}
Introduction
The Research School for Animal Production and Health (RAPH) was set up in 1998 as a sibling to the Research Centre for the Management of Animal Production and Health (CEPROS). CEPROS will be described later in the ICPD programme by its director, Dr. H. Houe. Both of these research organisations were created because it was felt, within Danish agriculture, that there was an urgent need to solve a number of multifactorial problems. The problems were connected with the increasing frequency of certain of production diseases, the spread of infectious zoonoses, such as salmonellosis, and the increasingly common occurrence of microbes with resistance to antibiotics. RAPH's primary contribution to the resolution of these issues was to educate researchers capable of solving the complex multidisciplinary problems associated with impaired animal health and welfare. In explaining how RAPH tries to meet this aim, I shall focus on issues relating to research education. The scientific detail of multidisciplinary research projects will be covered by Dr Houe. I shall look particularly at our early experiences - both good as bad - and discuss the role of research schools in the education of agricultural researchers.
\end{abstract}

\section{Formal organisation of RAPH}

RAPH was an initiative of The Royal Veteri- nary and Agricultural University undertaken in collaboration with CEPROS and the former National Research Academy. The research school is a formal subdivision of Graduate School for Veterinary and Agricultural Sciences in Denmark. It has its own PhD programme, which operates under the auspices of the general $\mathrm{PhD}$ programme of the Graduate School (Figure 1). RAPH also has its own Head, a scientific board and budgetary autonomy. Thirty-seven students are currently enrolled in the programme, and nine more will be enrolled during the remaining project period, which expires 2002.

\section{Objective}

The principal objective of RAPH is to attract and train PhD students in multidisciplinary aspects of animal health and production. The school also aims to encourage greater collaboration between university research centres in $\mathrm{PhD}$ training. In pursuing these aims, RAPH is committed to exploring new ways of organising $\mathrm{PhD}$ education.

\section{Multidisciplinary research projects}

The multidisciplinary research characteristically pursued within RAPH and CEPROS involves complex agriculturally related problems which, typically, are new, fundamental or of strategic value. While performing fundamental 
or strategic research at the highest level, doctoral students at RAPH must also acquire substantial insight into adjacent research fields in order to integrate their work within a broader frame of reference. Thus students are expected to develop and work with ideas which cross the traditional disciplinary borders. Indeed this is what is meant in the present context by 'multidisciplinary training'.

Research projects within RAPH are orientated around three principal research clusters. These are as follows:

Cluster A: Management of animal health and production

Cluster B: Pathogenesis of production diseases

Cluster C: Animal health economics

At any given time several projects will run within each cluster. The core of a RAPH research profile will, however, normally be situated where research clusters meet or intersect. This means that it will sometimes be difficult to assign a certain project to just one research cluster.

In general RAPH aims to facilitate and encourage continual interplay between, on the one hand, the highly specialised research disciplines within each of these clusters, and on the other hand, the multidisciplinary perspectives which arise in areas of overlap.

\section{Cluster A: Management of animal health and production}

Efforts to harmonise the demands of animal health and farm productivity are both central to Danish agriculture and increasingly demanded by Danish society. Research undertaken in this core area focuses on the development of profitable animal husbandry systems which respect, or promote, the health and welfare of livestock. Research identifying animal and herd health parameters is currently needed. Such parameters might be clinical, ethological or biochemical in nature. They might well involve production data. It goes without saying that there is a connected need for more precise methods of measuring the health of animals kept under existing management systems. Relevant objectives in this area can be defined on the basis of welfare, economic factors, human health relevance, research-related or other criteria. They might combine more than one of these criteria. Any survey and analysis will demand extensive, continuous clinical and laboratory investigations as well as any investigations needed for immediate practical purposes. In addition to a more precise determination of a herd's state of health, it is necessary to explain the importance of the production conditions, including housing and stable layout, climate and management factors.

Cluster B: Pathogenesis of production diseases In this context 'pathogenesis' refers to the process, or conditions, giving rise to disease during production. Research in this core area aims to deepen our understanding of the origin of diseases so that they can be controlled. Strategically, the control of production diseases depends on the development of methods by which pathological factors can be identified and evaluated. Knowledge of the immune system of the production animals is necessary if improved prevention strategies for the most important multifactorial diseases are to be developed. There is also a need to improve our understanding of both the specific and the non-specific immunity of the individual animal in relation to production conditions including type of housing, climate, feeding and other management factors. Through this, methods for improving immunity to disease will eventually be developed. Connectedly, levels of health in production animals will be raised. At present we lack 
methods for preparing detailed characterisations of herd immunity.

\section{Cluster C: Animal health economics}

Animal health economics is a relatively new research discipline. From an economic angle, it explores methods and tools decision-makers can exploit in selecting strategies of disease control. This discipline requires integrated contributions from animal science, veterinary science and commercial economics. Animal scientists have traditionally regarded the production process as the transformation of feed inputs into sellable outputs such as milk and meat. In contrast with this science-led approach, economists include other inputs, such as labour, buildings, machinery and management skills. Again, for many years veterinary science dealt solely with the treatment of individual animals. Over the last 20 years, however, epidemiology has expanded and developed, and within veterinary research the incidence and prevalence of, and production losses occasioned by, diseases have been studied more carefully. It is noticeable that many of the findings of these studies have not yet been integrated and utilised in a holistic way. As a result the full impact of diseases on animal production, and hence the economic output in a certain system, has rarely been properly evaluated. A major aim within the animal health economics core in RAPH is to develop methods by which disease control strategies can be steered as directly as possible at herd level. Within this research profile certain areas of research are particularly lively at present. These include the study of certain well-known production diseases, such as Salmonellosis, paratuberculosis, PRRSV and mastitis. Familiar methodologies are also being researched vigorously, especially those connected with health status: evaluation, surveillance, the relationship between disease and management factors, and welfare assess- ments. Research on antibiotics and antimicrobial resistance, on the definition of immunity in health and disease, the pathogenesis of viral diseases and metabolic aspects of production, is also intensive.

A list of the research projects in RAPH can be seen at www. raph.dk

\section{Outline of a RAPH PhD curriculum}

The general rules governing $\mathrm{PhD}$ studies in Denmark apply within RAPH. The following additional rules apply specifically, however, to RAPH studies:

- Each student must have 2 supervisors, one (the lead supervisor) from KVL and one from another research institution. Students are expected to spend a minimum of between 2 and 3 months at each supervisor's institution. For students affiliated to one of the research institutions, the period at KVL will normally carry some teaching commitments.

- Students must participate in a minimum of 2 Summer Schools arranged by RAPH.

- All students must participate in biannual seminars, arranged by RAPH and the other institutions with which students are registered.

- Each student should spend a minimum of four, and preferably six, months at a research institution abroad.

- Students must achieve a minimum of 30 ECTS points on their $\mathrm{PhD}$ courses. They may gain a maximum of 60 ECTS points.

- All students must pass a course in the "Ethics in Science". This course is devised within RAPH.

- All students must pass a course in Advanced Statistics.

- Successful RAPH students will receive a special $\mathrm{PhD}$ diploma, stating both the thematic content of their education and their research area. 


\section{The Scientific Panel and other advisors}

The Head of RAPH works with a group of scientists, known collectively as the Scientific Panel, in planning activities within RAPH. Members of this group are key persons within research areas covered by CEPROS. The Panel has been appointed for a period of five years by the CEPROS board. It assists the Head of RAPH with scientific evaluation of $\mathrm{PhD}$ applications, education programmes and $\mathrm{PhD}$ theses. It also contributes to the planning of seminars and summer schools. From time to time it may invite special advisors to participate in its work.

\section{Current membership of the Scientific Panel}

Chair. Dr. Pia Haubro Andersen, Associate Professor, DVM, PhD, DVSci, Head, Research School for Animal Production and Health, KVL, Frederiksberg, Denmark. (Veterinary clinical sciences).

Other Panellists. Dr. Niels Agergaard, DVM, dr.med.vet., Research Director, Danish Institute of Animal Sciences, Foulum, Denmark. (Animal physiology).

Dr. Jens Nielsen, DVM, PhD, Senior Researcher, Danish Veterinary Institute of Virus Research, Lindholm, Denmark. (Immunology and viral diseases).

Dr. Kristian Møller, DVM, PhD, Research Director, Danish Veterinary Laboratory, Copenhagen, Denmark. (Microbiology and parasitology).

Dr. Henrik B. Simonsen, DVM, dr.med.vet., Assistant Professor, Institute of Animal Production and Health, KVL, Denmark. (Ethology and animal welfare).

Dr. Lars Gjøl Christensen, dr. agro, Professor, Institute of Animal Production and Health, KVL, Denmark. (Animal breeding and genetics).

Dr. Ib M. Skovgaard, dr. scient. Professor, Insti- tute of Mathematics and Physics, KVL, Denmark. (Statistics)

Permanent visiting professors. Dr. Jeanne Burton, Department of Animal Science, Michigan State University, USA (Immunology, nutrition and genomics).

Dr. Paul Coussens, Department of Animal Science, Michigan State University, USA (Molecular biology and genomics).

Professor Dr.h.c. mult. Marian Horzinek, University of Utrecht, The Netherlands (Quality assessment and international relations).

Professor. John McInerney, Agricultural Economics Unit, University of Exeter, UK (Animal health economics).

Professor Dirk Pfeiffer, London, UK (Epidemiology and Risk Analysis).

Professor David Platt, University of Glasgow, UK (Microbiology).

\section{Discussion}

Today agriculture is one of Denmark's most successful and important economic sectors. The strength of the Danish agricultural economy has complex origins. However, there can be little doubt that during the last 20 years Danish farmers have benefited enormously from the rapid take-up of new technologies emerging from agricultural research. Throughout this period the principal aim of the expanding Danish agricultural research sector was increased production; but in recent years there has been a change in emphasis, away from food output, and towards subjects such as animal welfare and food quality and safety.

The creation of a research school to meet these new demands was a bold initiative, and at first it was met with a certain amount of scepticism. The very name 'research school' appeared provocative to many researchers. Research, as a profession, was viewed as an alternative to teaching and schools. It was therefore assumed 
that PhD students should not take classes, but perform research. Equally, there were no research schools in Denmark and hence the initiative had no model. This made it seem even more obscure. The exact meaning of the words 'research school' is still debated in Scandinavia. No single, agreed definition exists. In RAPH we have therefore decided that our research school should be regarded as a $\mathrm{PhD}$ programme with a certain profile and a certain structure to support this profile.

The scepticism has gradually diminished as it has become clear that academic freedom is not threatened where a profile is actively supported by the School. It is also widely accepted now that research students benefit from the courses they attend, and that a certain amount of structured teaching and the deliberate provision of research tools improves academic performance. It soon became clear, in any case, both that 'new' topics, such as Ethics in Science, required a class-based approach and that interdisciplinary insight would best be fostered in a group of students from different research disciplines.

Other critics have worried that the Danish $\mathrm{PhD}$ curriculum lasts only three years. It is a very short time span, and besides insisting on attendance at mandatory courses, we encourage the students to go abroad, to engage energetically with the School, and to follow our seminars and summer schools. This worry has much to be said for it. The compression of the curriculum indeed seems to be one the major drawbacks of the School's programme today.

RAPH and its rules were formulated with today's problems in Danish agriculture in mind. It was felt that if these recalcitrant, multifactorial problems were be attacked with success, it would need to be in any equally recalcitrant, multidisciplinary setting! Researchers working in this kind of setting must be prepared to work across traditional borders, and to meet the daily challenges that arise from such collaboration. They must enter into effective communication with colleagues who, disciplinarily speaking, talk another language - and who sometimes appear to be from another planet.

\section{Interdisciplinarity}

Methods for achieving real multidisciplinarity in research have yet to be defined. However, the experience of this research school is that the inspiration of dedicated and broadminded researchers is an important ingredient of success. Another important element is awareness of all aspects of a problem. Here it is necessary to distinguish between research and knowledge. On a traditional conception of academic endeavour, research at the highest level cannot, by definition, be interdisciplinary. For it is part of what we mean by 'high level research' that individual problems are addressed in great detail. Interdisciplinarity belongs to a system which operates above the research process itself. Interdisciplinarity is about the context and planning of research. Those defining research projects need an in-depth understanding of more than one aspect of a problem in order to ask the meaningful kinds of question that are imperative to the achievement of progress. One core task of RAPH is therefore to promote interdisciplinary understanding of the complexity of the agricultural problems. It is one of the most difficult tasks we face. At all meetings and biannual interdisciplinary seminars, students are encouraged to 'surface' from their deep wells and to give and receive feed-back with researchers and students from 'foreign' disciplines: the epidemiologist advises the animal health economist, who again advises a virologist on the economic feasibility of a certain test etc. RAPH students gain wide-ranging competence and an insight into many methods of animal production research, with a particular awareness of issues in animal health and welfare. It is hoped and ex- 
pected that this will ensure that RAPH PhDs are attractive applicants for positions in a variety of organisations.

Societal attitudes to methods of production and food processing are part of the complex of problems connected with agriculture and food in Denmark today. They provide the background to a proper understanding of the ethics of animal production, a topic considered to be a core concern within RAPH.

\section{Ethics in animal production}

One mandatory course - the "mandatory curse", as it is nicknamed by the students - is Ethics in Science. Many academics working in agricultural and veterinary fields today have a rather limited appreciation of the ethics involved in their decisions as researchers. They tend to believe that ethics merely is a matter of how well, or how badly, you treat your experimental animals. This course aims to enable the student to analyse a range of ethical and methodological problems that characteristically arise in research covering livestock production and health. Topics include general animal ethics; the ethics of livestock production; ethics in the interaction of research and livestock production; and related ethical problems. RAPH students are expected to become conversant with a wide range of research traditions. They also look at the interaction between individual scientists and topics such as conflict between researchers, scientific fraud, copyright and authorship. The ethics of collaboration and communication at all levels is also covered in this course. Each student has to prepare a written report on an ethical issue arising from his or her own project. It is our experience that this course is among those most highly appreciated when the students leave.

\section{Network and identity}

The mandatory courses and meetings have helped to build a strong network among RAPH students. Lack of access to a network is known to be one of the most devastating factors in many $\mathrm{PhD}$ programmes, as is shown in both national and international evaluations of $\mathrm{PhD}$ programmes. My experience is that $\mathrm{PhD}$ students are frequently frustrated by their research situation: things are not going as fast as planned, the project has its own will, the supervisor is not as great a help as initially hoped. Recourse to a network is of the utmost importance, not only during the $\mathrm{PhD}$ years, but as a habit that will endure through the individual's whole research life.

It is a general finding in many questionnaires and surveys of the $\mathrm{PhD}$-supervisor relationship that many students are quite disappointed by their relationship to the supervisor. The student may feel that his or her supervisor is too busy and sometimes fails to pay enough attention to the project. Of course, this also happens in RAPH, but in our experience RAPH students have managed such situations by using their networks.

Within RAPH efforts are made to foster a distinctive sense of identity as well as individuality. Some of the many skills a researcher requires cannot be taught in classes and during courses. A research school can therefore achieve nothing without effective supervisors. The supervisor has daily contact with the student. He or she takes responsibility for the way in which the project is conducted and ultimately concluded. It is therefore of great importance that there is a continuous dialogue - for example, regarding the concept of research quality between students and their supervisors. What is high quality in research? How is it perceived in Denmark? How is it perceived in other countries? This dialogue has been much harder to guarantee than we thought. It is something that we need to improve on. 


\section{Will RAPH make a difference?}

To answer this: we cannot know yet, but we retain a strong believe in the project. Students are certainly being attracted to the programme. They are now networking without assistance from RAPH. The feedback from supervisors and other researchers is also generally positive. The creation of this research school has inspired a number of other initiatives in Denmark. Upon request the two most common pieces of advice we offer are:

1. Select only quality (persons, projects, students, programmes, funding and so on).

2. If there is no real enthusiasm among the persons who are to carry out an idea, drop the idea.
These two pieces of advice reflect our present self-evaluation. With them, I would like to conclude this brief survey of RAPH.

The RAPH experiment will be evaluated next year. Many different measures of quality will probably be applied - bibliometric analyses of student publications, statistical analysis of time and money spent, and so on. But the real impact of interdisciplinary training may not be visible until, ten years from now, the present students have become research leaders. It is a bit like forestry: a long term task.

Contribution to 11. International Conference on Production Diseases in Farm Animals, 12-16 August 2001, The Royal Veterinary and Agricultural University, Frederiksberg, Denmark.

Reprints may be obtained from: Pia Haubro Andersen, Dept. Clinical Studies, The Royal Veterinary and Agricultural University, Dyrlægevej 48, DK-1870 Frederiksberg C, Denmark. 